\title{
Where Next at Geneva?
}

Whatever else may have happened, the past few months have been exceedingly cheerful for those concerned to see a faster move towards international agreements on arms control and disarmament. The way in which the approval of the non-proliferation treaty by the United Nations General Assembly seems to have loosened a log-jam fits in well with the view that the chief benefit of that agreement would be to prepare the ground for more ambitious and indeed more meaningful measures. In practical terms, the protestations of the non-nuclear powers which participated in the long negotiations of the treaty in Geneva seem to have had some effect. Although the treaty makes no concession to the view that if the non-nuclear powers are bound to abstinence, then the freedom of the nuclear powers to throw their weight about should also be restricted, both the Soviet Union and the United States seem to accept the need for limitations on the numbers of strategic weapons deployed against the other side. An agreement on this point should be much more valuable than any benefit which the nonproliferation treaty as such may eventually provide. The defects of that treaty remain more or less what they have always been-that the methods of inspection are cumbersome and potentially even unworkable, that the treaty threatens permanently to institutionalize the differences between the nuclear and the nonnuclear powers and, finally, that the treaty is only likely to work so long as there is no compelling reason why signatories should break ranks. It remains to be seen what pressures to this end may eventually be created by the predictable abstentions from the list of signatories--France and mainland China. But issues like these are clearly of only academic interest if the non-proliferation treaty has really paved the way for better things. Even if it represents the triumph of good intentions over harsh reality, nobody should complain.

The proposal for discussions between the Soviet Union and the United States on the limitation of strategic missiles is potentially exceedingly important, but it would probably be wrong to separate this development from the discussions in the past twelve months of the development of anti-missile systems in both countries. Although the development of hardware in the United States is still at a very early stage, and although it is unlikely that things have gone much further in the Soviet Union, the chances are that both governments are worried by the long term implications of this development.

To begin with, there is the cost, and even the superpowers must flinch at the prospect of the money that would be consumed by a successful development and installation of a comprehensive anti-missile system.
By that standard, what has been spent so far is only a small drop in the ocean. More seriously there is a danger that effective anti-missile defences could upset the present stability or illusion of stability between the strategic powers. Both of them seem in the past few years to have acquired a missile striking force which could probably ride out an attack by the other side, with the result that the hasty moves and countermoves which characterized the planning for the first nuclear wars in the early fifties has become a kind of hairraising nightmare. On paper, at least, nations can make plans to see that nuclear weapons are a last resort and both of them have an interest in doing just that. Anti-missile defences are potentially worrying because they suggest that in certain circumstances the effectiveness of this last resort might be reduced-a development which is likely to make both the Soviet Union and the United States begin planning all over again to use nuclear weapons as rapid responses. If this, however, is the origin of the tacit understanding that there should now be some limitation on strategic armament, it is also important that the search for an agreement should not be pursued with too much zeal. Limiting strategic missiles to, say, fifty would also destroy the stability of the present system, in which the invulnerability of strategic striking forces is partly dependent on their numerical strength. Probably the best course would be to fix a very much larger number as a limit for the total on each side of strategic missiles of all kinds-offensive and defensive.

None of this will be hammered out at the meetings of the Disarmament Committee in Geneva. There, now, the non-nuclear powers which predominate will find themselves looking for other formulae for agreement. The prospects for an underground test ban are brightening all the time and it is to the British Government's credit that Mr Fred Mulley from the Foreign Office reminded the conference, earlier this week, of the need to begin talking about chemical and biological weapons. That is obviously a potentially most fruitful field. But in the immediate future, it is hard to see why discussions on disarmament move warily around what is rapidly becoming one of the ripest plums for picking-some kind of limitation on the rate of manufacture of nuclear explosives. The Disarmament Committee would do well to look at this problem from the point of view of a cost-benefit analysis. The policing of the non-proliferation treaty will involve elaborate arrangements for inspection and control in all kinds of factories concerned with making nuclear explosives, and very little elaboration of the system would be required to police an agreement not to use fissile material for military purposes. Such an agreement should be technically easy to obtain. 